Article

\title{
Synthesis, Structure, and Photophysical Properties of Yellow-Green and Blue Photoluminescent Dinuclear and Octanuclear Copper(I) Iodide Complexes with a Disilanylene-Bridged Bispyridine Ligand
}

\author{
Toyotaka Nakae (D), Hiroto Miyabe, Masaki Nishio, Teppei Yamada and Yoshinori Yamanoi *
}

Department of Chemistry, School of Science, The University of Tokyo, 7-3-1 Hongo, Bunkyo-ku, Tokyo 113-0033, Japan; nakae@chem.s.u-tokyo.ac.jp (T.N.); s2-6-hmiyabe@g.ecc.u-tokyo.ac.jp (H.M.); m-nishio@chem.s.u-tokyo.ac.jp (M.N.); teppei@chem.s.u-tokyo.ac.jp (T.Y.)

* Correspondence: yamanoi@g.ecc.u-tokyo.ac.jp; Tel.: +81-3-5841-4348

Citation: Nakae, T.; Miyabe, H.; Nishio, M.; Yamada, T.; Yamanoi, Y. Synthesis, Structure, and Photophysical Properties of Yellow-Green and Blue

Photoluminescent Dinuclear and Octanuclear Copper(I) Iodide

Complexes with a

Disilanylene-Bridged Bispyridine Ligand. Molecules 2021, 26, 6852. https://doi.org/10.3390/ molecules 26226852

Academic Editors: Hiroshi Nishihara and Hiroaki Maeda

Received: 31 August 2021

Accepted: 3 November 2021

Published: 13 November 2021

Publisher's Note: MDPI stays neutral with regard to jurisdictional claims in published maps and institutional affiliations.

Copyright: (C) 2021 by the authors Licensee MDPI, Basel, Switzerland. This article is an open access article distributed under the terms and conditions of the Creative Commons Attribution (CC BY) license (https:// creativecommons.org/licenses/by/ $4.0 /)$.

\begin{abstract}
The synthesis, structural, and photophysical investigations of CuI complexes with a disilanylenebridged bispyridine ligand $\mathbf{1}$ are herein presented. Dinuclear (2) and ladder-like (3) octanuclear copper(I) complexes were straightforwardly prepared by exactly controlling the ratio of CuI/ligand 1 . Singlecrystal X-ray analysis confirmed that dinuclear complex 2 had no apparent $\pi \ldots \pi$ stacking whereas octanuclear complex 3 had $\pi \ldots \pi$ stacking in the crystal packing. In the solid state, the complexes display yellow-green $\left(\lambda_{\mathrm{em}}=519 \mathrm{~nm}, \Phi=0.60, \tau=11 \mu \mathrm{s}, 2\right)$ and blue $\left(\lambda_{\mathrm{em}}=478 \mathrm{~nm}, \Phi=0.04, \tau=2.6 \mu \mathrm{s}\right.$, 3) phosphorescence, respectively. The density functional theory calculations validate the differences in their optical properties. The difference in the luminescence efficiency between $\mathbf{2}$ and $\mathbf{3}$ is attributed to the presence of $\pi \ldots \pi$ stacking and the different luminescence processes.
\end{abstract}

Keywords: disilanylene-bridged chelating ligand; copper(I) iodide; photoluminescence

\section{Introduction}

$\mathrm{Cu}(\mathrm{I})$-based emitters are considered as an attractive alternative to those containing platinum group metals for the development of luminescent materials because copper is abundant and inexpensive compared to other noble metals [1-11]. Due to their flexible coordination properties, $\mathrm{Cu}(\mathrm{I})$ halides-aggregates have been incorporated in coordination oligomers or polymers, which exhibit a range of photophysical properties [12-15]. Pyridine and its derivatives are one of the most investigated ligands for the copper(I) iodide complexes [16,17]. In general, the structural motifs of the core are dependent on the electronic and steric properties and stoichiometry of pyridine ligands, and the core structure affects the luminescent properties of the copper(I) iodide complexes. Besides the molecular structure, the intermolecular interaction is also critical for the luminescence properties of the copper(I) iodide complexes because strong intermolecular interactions, such as $\pi$ $\ldots \pi$ stacking, in the solid state strongly suppress the luminescence as seen in copper iodide complexes with 2,2'-bipyridyl or 1,10-phenanthroline ligands [18-23]. Therefore, the control of the intermolecular interaction in copper(I) iodide complex is also crucial for efficient luminescent materials.

We recently investigated aromatic compounds connected with disilanylene groups $\left(-\mathrm{SiR}_{2} \mathrm{SiR}_{2}-\right)$ [24-33]. Disilanylene-linkers extend the conjugated system through $\sigma-\pi$ interaction, similarly to $\mathrm{C}=\mathrm{C}$ double bonds. On the other hand, the disilanylene moiety acts as a bulky group due to the tetrahedral geometry at silicon atoms and substituents on $\mathrm{Si}$, and the single bond character of the Si-Si bond allows the rotation along with the Si-Si bond, which are different from the planar and rigid $\mathrm{C}=\mathrm{C}$ double bond. These steric features of the disilanylene linker suppress the strong intermolecular $\pi \ldots \pi$ stacking and give unique properties, typically in the solid or aggregated states $[34,35]$. The use of disilanylene is a 
possible candidate for a linker moiety to control intermolecular interactions; the bulkiness will suppress strong intermolecular interaction and the long Si-Si distance will give a large bite angle compared with the $\mathrm{C}-\mathrm{C}$ bond analogues. There are some complexes with disilanylene-bridged ligands, and they show unique structure and properties, such as $\sigma$-coordination of the Si-Si bond [36], multiple switchable crystal polymorphs in a metalorganic framework [37], and photo-induced crystalline transformation [38]. However, the use of chelating disilane-based ligands was still limited.

A variety of inorganic building motifs have been reported for copper(I) with organic ligands. We herein report di- and octanuclear copper(I) iodide complexes with a disilaylenebridged bispyridine bidentate ligand, 1,1,2,2-tetramethyl-1,2-di(pyridin-2-yl)disilane (1). The linker moiety in $\mathbf{1}$ is 1,1,2,2-tetramethyldisilanylene, which can act as a bulky linker as mentioned above. The copper(I) iodide complexes of $\mathbf{2}$ and $\mathbf{3}$ were selectively obtained by the stoichiometric control of copper(I) iodide and showed light blue and yellow-green photoluminescence in the solid state. To rationalize the different optical properties observed, quantum chemical calculations were performed for two copper clusters.

\section{Results and Discussion}

\subsection{Synthesis and Crystal Structure of $\mathrm{Cu}$ Complexes 2 and 3}

The disilanylene-bridged bispyridine ligand 1 was synthesized by a reaction of 2pyridyllithium with 1,2-dichloro-1,1,2,2-tetramethyldisilane. The structure was determined by ${ }^{1} \mathrm{H}$ and ${ }^{13} \mathrm{C}$ NMR (Figures S7-S10) and high-resolution mass spectroscopy. The dinuclear copper(I) iodide complex $[\mathrm{Cu}(\mu-\mathrm{I})(\mathbf{1})]_{2}(2)$ was obtained by a reaction of copper(I) iodide and 1 in acetonitrile in a 1:1 ratio (Scheme 1a). The complex 2 was isolated as an air-stable pale-yellow solid. Single crystals were obtained by recrystallization from dichloromethane and $n$-hexane. Elemental analysis of $\mathbf{2}$ gave the expected composition. Single-crystal $X$-ray diffraction analysis revealed that the molecular structure consists of bimetallic iodo-bridged neutral complex $[\mathrm{Cu}(\mu-\mathrm{I})(\mathbf{1})]_{2}$, and selected bond distances and angles are shown in Figure 1. The complex was crystallized in the triclinic space group $P-1$, and the asymmetric unit (half of the complex) was related with an inversion center. Two copper atoms were bridged by two iodo ligands, and each copper center was supported by a bidentate ligand 1 in an $\mathrm{N}_{2} \mathrm{I}_{2}$ distorted trigonal pyramidal geometry. The $\mathrm{Cu} 1$ atom positioned $0.315 \AA$ out of the basal plane defined by N1, N2, and I1 toward I2. The torsion angle of the disilane moiety (C(pyridine)-Si-Si-C(pyridine)) is $98.51(8)^{\circ}$, which indicates the staggered conformation of the disilane moiety. The distance of two copper atoms (3.8761(3) $\AA$ ) was longer than the double of the covalent radius of copper $(1.32 \AA)$, which suggested the negligible direct $\mathrm{Cu}$... Cu interaction [39,40]. The Si1-Si2 distance (2.3441(7) $\AA$ ) was in the normal range of $\mathrm{Si}$-Si bonds, and the $\mathrm{Cu}$... Si distances were larger than the sum of the van der Waals radii of $\mathrm{Cu}$ and $\mathrm{Si}$, suggestive of the absence of $\sigma$-bonding interaction between the $\mathrm{Cu}$ and Si-Si bond [36]. The Cu-I distances (2.7405(3) and 2.9689(3) $\AA$ ) are significantly larger than those of related complexes with a $\mathrm{Cu}_{2} \mathrm{I}_{2}$ core [41-44]. The $\mathrm{Cu}-\mathrm{N}$ distances (1.987(2) and 1.993(2) $\AA$ ) are slightly shorter than usual (2.02 $\AA$ for unsubstituted pyridine analogue), and the N1-Cu-N2 bite angle in the complex was $140.45(6)^{\circ}$, ideally $120^{\circ}$ in a trigonal pyramidal geometry. This large bite angle possibly affects the long Cu-I bond in the $\mathrm{Cu}_{2} \mathrm{I}_{2}$ core because it makes the distance between the methyl groups on the linker and iodide ligands shorten to induce the steric repulsion (the shorter $\mathrm{C}(\mathrm{Me})$... I distance was 4.196(2) A). The crystal packing pattern of 2 shows columns along with the $c$-axis. From the viewpoint of crystal packing, $\mathrm{CH} \ldots \pi$ interactions were observed between methyl groups and pyridine rings, similarly to other disilyene-connected aromatic compounds (Figure S1) [45]. It is noteworthy that no significant $\pi \ldots \pi$ stacking was observed in the crystal packing (the intermolecular distance of adjacent pyridine-ring centroids: $4.31 \AA$ ), suggesting that the bulky linker moiety suppress the undesirable intermolecular $\pi \ldots \pi$ stacking as designed (Figure S3). We measured the powder XRD of $\mathbf{2}$. The comparison of the diffraction pattern between the powder and single crystal of $\mathbf{2}$ is shown in Figure S6a. We did not observe any major changes in the diffraction pattern. 
a)<smiles>C[Si](C)(c1ccccn1)[Si](C)(C)c1ccccn1</smiles>

1

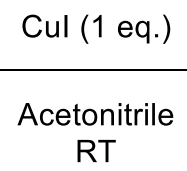

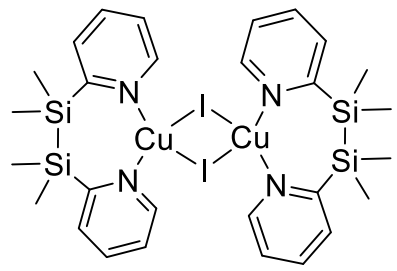

2

b)<smiles>C[Si](C)(c1ccccn1)[Si](C)(C)c1ccccn1</smiles>

1
Cul (2 eq.)

Acetonitrile RT

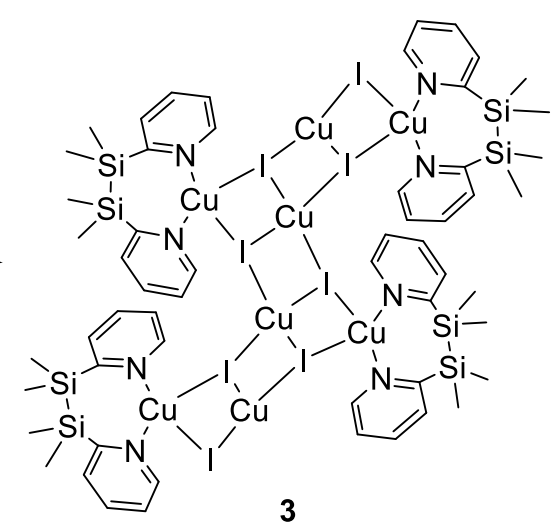

Scheme 1. Reactions of bispyridine ligand 1 with copper iodide in 1:1 ratio (a) and 1:2 ratio (b).

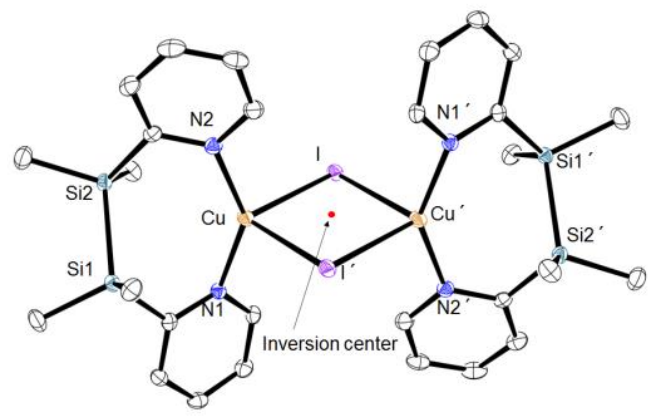

Figure 1. ORTEP drawing of complex 2 with thermal ellipsoids at the $50 \%$ probability level. Hydrogen atoms were omitted for clarity. Selected bond lengths and angles. Cu ... Cu': 3.8761(3) $\AA$. Cu-I:

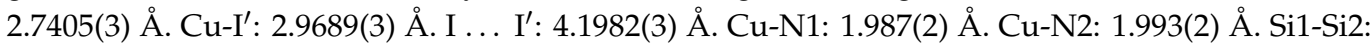

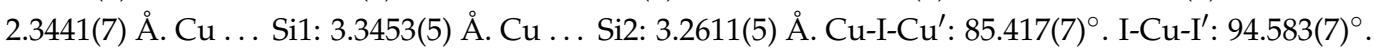
N1-Cu-N2: $140.45(6)^{\circ}$.

Octacopper(I) iodide complex $\left[\mathrm{Cu}_{4} \mathrm{I}_{4}(\mathbf{1})_{2}\right]$ (3) was obtained by a reaction of ligand 1 and $\mathrm{CuI}$ in a 1:2 ratio (Scheme $1 \mathrm{~b}$ ). Elemental analysis of 3 gave the expected composition. The single crystals suitable for $\mathrm{X}$-ray diffraction were obtained by recrystallization from tetrahydrofuran and $n$-hexane. Complex 3 crystallized in the monoclinic space group $P 2_{1} / c$. The crystal structure of 3 is shown in Figure 2, which can be interpreted by a dimer of a ladder $\left[\mathrm{Cu}_{4} \mathrm{I}_{4}(\mathbf{1})_{2}\right]$ cluster. In the asymmetric unit of complex 3 , three copper centers (Cu1, Cu2, and Cu4 in Figure 2) have a quasi-tetrahedral environment, and the other (Cu3) has quasi-trigonal planar geometry. These copper centers are bridged by three $\mu_{3}-\mathrm{I}$ and one $\mu_{2}$-I ligands, and the copper centers at the apical positions are supported by chelating ligand 1. The $\mathrm{Cu}-\mathrm{I}$ bond distances of the trigonal planar copper(I) center $(2.50-2.56 \AA)$ are in the normal range of those of $\mathrm{Cu}-\mathrm{I}$ complexes [46-48]. Similarly to complex 2, the $\mathrm{Cu}-\mathrm{I}$ bond lengths of copper centers supported by ligand 1 (Cu1-I1, 2.8580(5) ^; Cu1-I2,

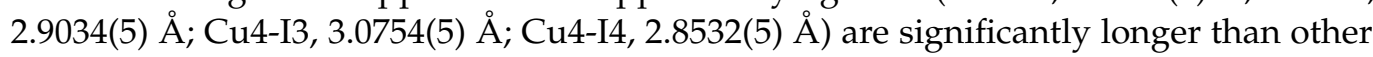
reported complexes. $\mathrm{Cu}$... Cu distances are also larger than the double of $\mathrm{Cu}(\mathrm{I})$ radius, suggestive of negligible $\mathrm{Cu}$... Cu interaction. The bite angles (N1-Cu1-N2, 143.19(11) ${ }^{\circ}$; 
N3-Cu4-N4, $143.83(11)^{\circ}$ ) of ligand 1 are slightly larger than that of complex 2 . We also measured the powder XRD of 3 . The comparison of the diffraction pattern between the powder and single crystal is shown in Figure S6b. The PXRD resulted in the peaks closed to XRD being simulated by the single crystal, although anisotropic peaks are observed due to the interplanar $\pi-\pi$ stacking in the crystalline packing of 3 .

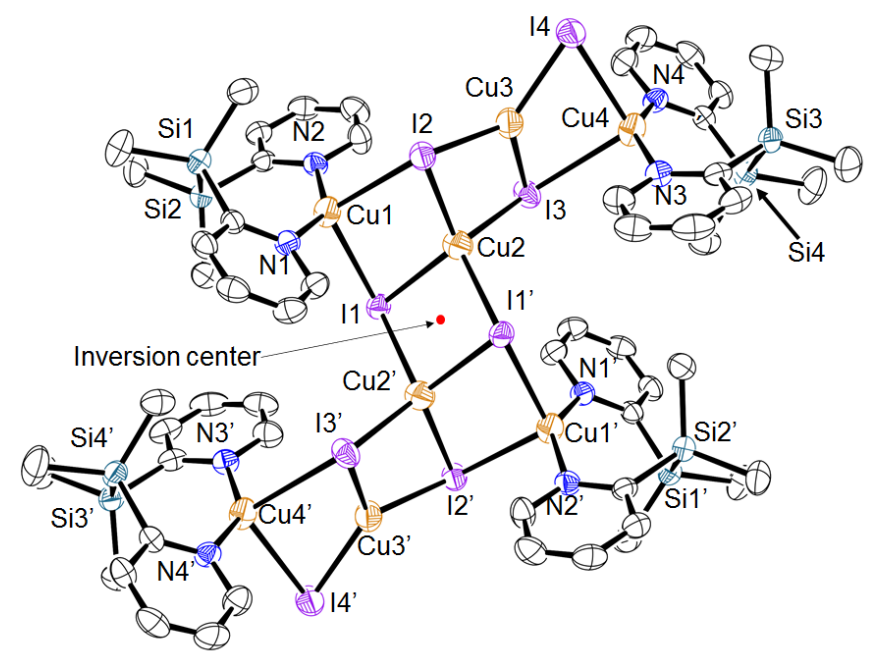

Figure 2. ORTEP drawing of complex 3 with thermal ellipsoids at the $50 \%$ probability level. Hydrogen atoms were omitted for clarity. Selected bond distances and angles. Cu1 . . Cu2, 3.0943(7) ^; Cu2

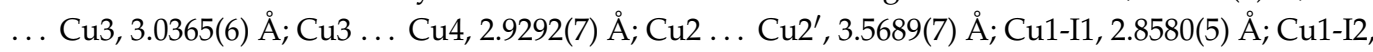

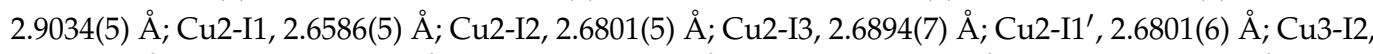

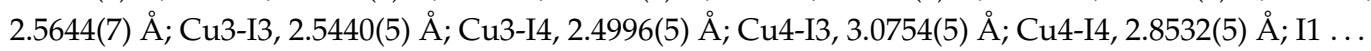

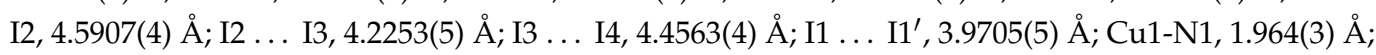

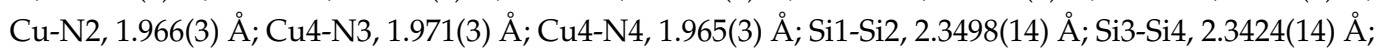

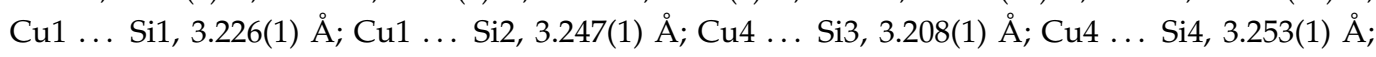
$\mathrm{Cu}-\mathrm{I}-\mathrm{Cu}^{\prime}: 85.417(7)^{\circ}$. I-Cu-I': 94.583(7) ${ }^{\circ}$. N1-Cu1-N2, $143.19(11)^{\circ}$; N3-Cu4-N4, $143.83(11)^{\circ}$.

Ladder-based copper iodide complexes with monodentate ligand generally gave coordination polymers, and some bulky pyridine ligands yielded tetracopper(I) iodide step complexes [49]. In the complexes with $N, N, N$-tridentate ligands, the ligands act as bridging ones for copper centers by $\eta^{2}$-coordination for the apical position and $\eta^{1}$-coordination for the side position [50-53]. In the case of the bidentate ligand 1, the side-positioned copper atoms ( $\mathrm{Cu} 3$ and $\left.\mathrm{Cu}^{\prime}\right)$ are not supported by the chelating ligand. Presumably, the vacant site is capped by the iodide of another tetracopper(I) cluster to form complex 3 . To the best of our knowledge, this dimerization of the ladder copper(I) iodide core seems to be a new core architecture in octanucler copper(I) iodide complexes. The crystal packing pattern of 3 shows columns along with the $a$-axis similarly to complex 2 and intermolecular $\pi \ldots \pi$ stacking of pyridine rings along with the $b$-axis (the intermolecular distances of adjacent pyridine-ring centroids: $3.93 \AA$ and $3.81 \AA$, Figures S2 and S4). All pyridine moieties in complex 3 are used for the stacking.

\subsection{Photophysical Properties}

We investigated the photophysical properties of 2 and 3 (Table 1). Figure 3 shows the excitation spectra, emission spectra, transient luminescence decay curves, and photographs under UV irradiation of $\mathbf{2}$ and $\mathbf{3}$ in the solid state. These $\mathrm{Cu}$ complexes did not display detectable photoluminescence in the solution state. This is in line with related copperhalide complexes, and it was ascribed to their chemical instability, owing to the flexible nature of the complex scaffold and ligand dissociation. Although most $\mathrm{Cu}(\mathrm{I})$ complexes with chelating pyridine-based ligands showed weak emission from the MLLCT excited state with low quantum yield, dicopper complex 2 showed broad and non-structured 
yellow-green $(519 \mathrm{~nm})$ emission in the solid state in good photoluminescent intensity ( $\Phi=0.60$, Figure 2) [54]. The luminescence wavelength and quantum yield of 2 are in a normal range of the dicopper(I) iodide complexes with a rhombic core, which rationalizes the initial molecular design $[55,56]$. Complex 3 also shows broad and nonstructured blue emission (478 nm, $\Phi=0.04)$ in the solid state. The emission wavelength of 3 is longer than that of the ladder-type polymer [CuI(4-picoline) $]_{\infty}(437 \mathrm{~nm})$ [57] due to the lower LUMO levels induced by the introduction of the Si-Si moiety [58-60]. The shapes of the spectra indicate the charge-transfer character of the emission. The lifetimes of the luminescence were $11 \mu \mathrm{s}$ for 2 and $2.6 \mu \mathrm{s}$ for 3 , respectively. The lifetimes in the order of $\mu$ s suggest that the origins of the emissions are phosphorescence in both 2 and 3.

Table 1. Luminescent properties of 2 and 3 in the solid state at room temperature.

\begin{tabular}{ccc}
\hline Complex & $\mathbf{2}$ & $\mathbf{3}$ \\
\hline$\lambda_{\mathrm{em}} / \mathrm{nm}$ & 519 & 478 \\
$\Delta v_{1 / 2} / \mathrm{eV}[\mathrm{a}]$ & 0.46 & 0.43 \\
$\Phi[\mathrm{b}]$ & 0.60 & 0.04 \\
$\tau / \mu \mathrm{s}$ & 11 & 2.6 \\
$k_{\mathrm{r}} / \mathrm{s}^{-1}[\mathrm{c}]$ & $5.5 \times 10^{4}$ & $1.5 \times 10^{4}$ \\
$k_{\mathrm{nr}} / \mathrm{s}^{-1}[\mathrm{~d}]$ & $3.6 \times 10^{4}$ & $3.7 \times 10^{5}$ \\
\hline
\end{tabular}

[a] Full width at half-maximum of the emission. [b] Absolute quantum yield excited at $380 \mathrm{~nm}$ in the solid state at room temperature. [c] Radiative rate constant calculated by $k_{\mathrm{r}}=\Phi / \tau$. [d] Nonradiative rate constant calculated by $k_{\mathrm{nr}}=(1-\Phi) / \tau$.

a)

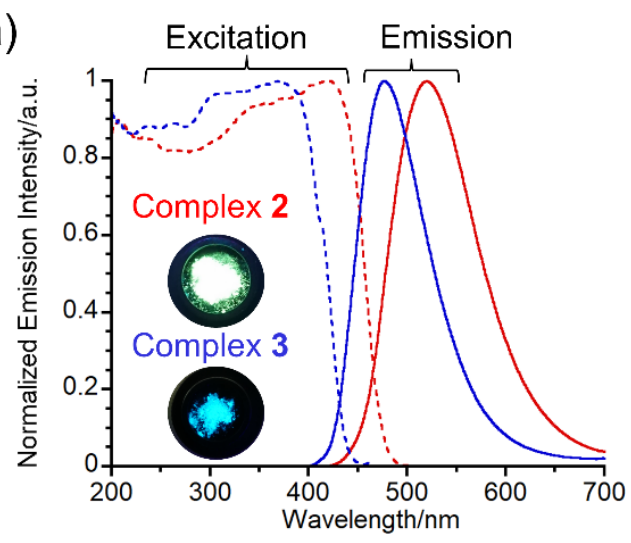

b)

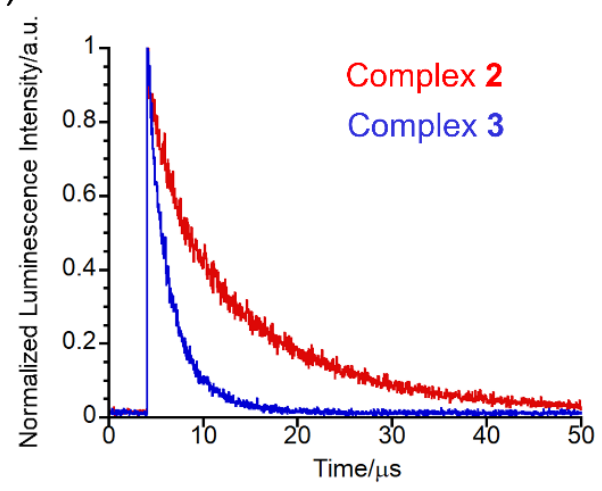

Figure 3. (a) Emission (solid lines, excited at $380 \mathrm{~nm}$ ) and excitation (dashed lines, observed at $519 \mathrm{~nm}$ for 2 and $478 \mathrm{~nm}$ for 3) spectra of 2 (red lines) and 3 (blue lines) in the solid state at room temperature. Photographs of 2 (top) and 3 (bottom) under $365 \mathrm{~nm}$ light irradiation. (b) Transient luminescence decay curves of $\mathbf{2}$ and $\mathbf{3}$ at room temperature.

\subsection{Theoretical Consideration}

Finally, we performed quantum chemical calculation based on density functional theory (DFT) to obtain some insight into the photophysical properties of complexes 2 and 3. The structure optimizations were performed with a B3LYP functional and LANL2DZ (for iodide) and 6-31g(d) (for others) basis sets, where initial structures were obtained from the crystal structures. The highest-occupied molecular orbitals (HOMOs) of $\mathbf{2}$ and $\mathbf{3}$ are located on the copper iodide cores, and the lowest unoccupied MOs (LUMOs) are spread over ligand 1 (Figure 4a). It is noteworthy that complex 3 has higher HOMO energy and lower LUMO energy compared with complex 2 , although the emission wavelength of 3 is shorter than that of $\mathbf{2}$ at room temperature. 

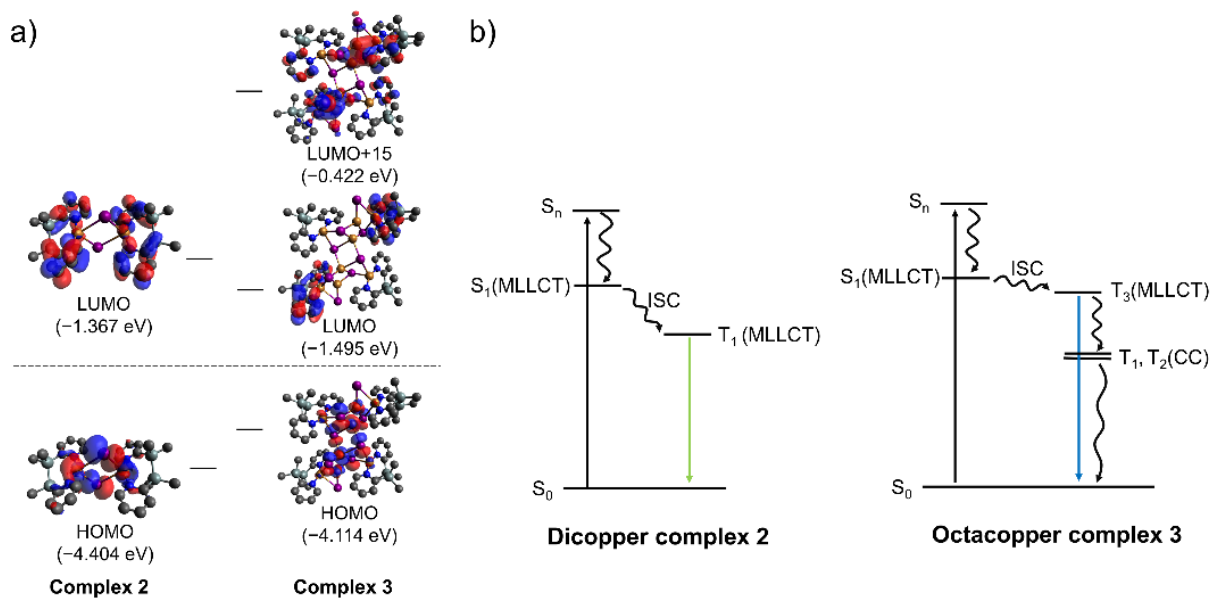

Figure 4. (a) Representative molecular orbitals and energy levels of $\mathbf{2}$ and $\mathbf{3}$ related to electronic transitions. (b) Plausible luminescent mechanisms of $\mathbf{2}$ and $\mathbf{3}$ at room temperature. Wavy lines indicate the nonradiative relaxation process.

To investigate the conflict of the energy gap and the emission wavelength in these complexes, we next performed time-dependent DFT (TD-DFT) calculations. Because complexes 2 and 3 showed phosphorescence, TD-DFT calculations were performed including triplet excitations (Figures S11 and S12 and Tables S2 and S3). The lowest energy singlet transitions of $\mathbf{2}$ and $\mathbf{3}$ were calculated as $\mathrm{HOMO} \rightarrow$ LUMO excitations, which corresponded to metal-ligand-to-ligand charge-transfer (MLLCT) transitions. The lowest triplet excitations, which should be related to the emission for these complexes, were the corresponding MLLCT excited state for the dicopper(I) complex 2 but a cluster-centered (CC) excited state for the octacopper(I) complex 3 (for example, HOMO $\rightarrow$ LUMO + 15 in Figure 4a). The corresponding ${ }^{3}$ MLLCT excited states of 3 were found at higher energy than the CC excited states and the MLLCT excited state of 2 . In some copper iodide complexes, dual emission from similar ${ }^{3} \mathrm{MLLCT}$ and ${ }^{3} \mathrm{CC}$ excited states has been reported [61]. Therefore, both ${ }^{3} \mathrm{MMLCT}$ and ${ }^{3} \mathrm{CC}$ excited states in $\mathbf{3}$ are also potentially emissive.

From these calculations, the plausible luminescence mechanisms of $\mathbf{2}$ and $\mathbf{3}$ at room temperature are shown in Figure $4 \mathrm{~b}$. In dicopper(I) complex 2, photoexcitation gives the lowest-energy singlet excited state ${ }^{1}$ MLLCT, which is relaxed to the ${ }^{3}$ MLLCT state via intersystem crossing (ISC) owing to the heavy atom effect of the copper iodide core. Because the ${ }^{3}$ MLLCT excited state is the lowest-energy triplet state in complex 2, emission occurs from the excited state. Similarly to 2 , photoexcitation of 3 leads to the formation of the ${ }^{1}$ MLLCT and ${ }^{3}$ MLLCT state, from which phosphorescence at a shorter wavelength than 2 can occur. However, the almost ${ }^{3}$ MLLCT excited state would be relaxed to the lowestenergy triplet excited state, the ${ }^{3} \mathrm{CC}$ excited state. Because only one emission was observed in emission spectrum of 3 , the ${ }^{3} \mathrm{CC}$ excited state may be quenched at room temperature via a nonradiative process, such as vibrational relaxation due to the loose $\mathrm{Cu}-\mathrm{I}$ core structure. The related ladder-type copper iodide cluster also shows phosphorescence derived from ${ }^{3}$ MLLCT at room temperature and a longer phosphorescence wavelength is observed at lower temperatures, suggesting a low-lying potentially emissive ${ }^{3} \mathrm{CC}$ excited state $[62,63]$.

The partial quenching mechanism via the ${ }^{3} \mathrm{CC}$ excited state would decrease the luminescent quantum yield of 3 . Therefore, the much lower quantum yield of $3(\Phi=0.04)$ than that of $\mathbf{2}(\Phi=0.60)$ at room temperature could originate from the nonradiative relaxation of the lowest excited state. Another possible explanation of the decrease in the luminescence intensity of 3 is the intermolecular $\pi \ldots \pi$ stacking in the crystal packing. In general, when $\pi$ $\ldots \pi$ stacking is present in the crystal packing, the excitation energy is delocalized among molecules, resulting in emission quenching through lattice defect [64-66]. The emission behavior of copper iodide clusters and their consideration in this study suggest the importance 
of the core architecture for emissive complexes. These mechanistic insights will provide a design for efficient luminescent materials based on copper iodide complexes.

\section{Conclusions}

In conclusion, we synthesized a disilane-bridged bispyridine ligand (1) and its dinuclear and octanuclear copper(I) iodide complexes ( 2 and 3 ) under the control of the stoichiometric ratio of 1 and CuI. Complexes 2 and 3 showed intense yellow-green $\left(\lambda_{\mathrm{em}}=519 \mathrm{~nm}\right.$, $\Phi=0.60, \tau=11 \mu \mathrm{s})$ and weak light blue $\left(\lambda_{\mathrm{em}}=478 \mathrm{~nm}, \Phi=0.04, \tau=2.6 \mu \mathrm{s}\right)$ photoluminescence in the solid state, respectively. Single-crystal X-ray diffraction analysis of $\mathbf{2}$ and 3 revealed that the bulkiness of the linker moiety in ligand 1 suppressed the intermolecular $\pi \ldots \pi$ interaction in 2 but did not suppress it in 3 . DFT and TD-DFT calculations suggest that the yellow-green emission of 2 originates from the lowest excited ${ }^{3}$ MLLCT state while the blue emission of 3 is not derived from the lowest-excited ${ }^{3} \mathrm{CC}$ state but from a higher-lying ${ }^{3}$ MLLCT excited state. Thus, the weaker emission of 3 compared with that of $\mathbf{2}$ is due to quenching by the intermolecular $\pi \ldots \pi$ stacking and the nonradiative decay of the lowest excited state $\left({ }^{3} \mathrm{CC}\right)$. These copper clusters with disilane-bridged bispyridine ligands in this work appear to be a promising tunable building block for application in photofunctional materials.

Supplementary Materials: The following are available online. The supplementary materials include Experimental Section, Crystal structures of complexes $\mathbf{2}$ and 3, NMR spectra of $\mathbf{1}$, Crystallographic data for $\mathbf{2}$ and 3, Results of quantum chemical calculations of $\mathbf{2}$ and $\mathbf{3}$.

Author Contributions: Investigation, T.N., H.M. and M.N.; writing—review and editing, Y.Y. and T.Y. All authors have read and agreed to the published version of the manuscript.

Funding: This work was financially supported in part by the Nagase Science and Technology Foundation, the Mikiya Science and Technology Foundation, the Yashima Environment Technology Foundation, Tonen General Sekiyu Research/Development Encouragement \& Scholarship Foundation, the Murata Science Foundation, the Tanikawa Fund Promotion of Thermal Technology, the Hokuto Foundation for Bioscience, the Hosokawa Powder Technology Foundation, a Grant-in-Aid for Scientific Research (C) (no. JP19K05627), and Scientific Research on the Innovative Area "Soft Crystal: Science and Photofunctions of Flexible Response Systems with High Order" (area 2903, no. JP17H06369) from the Ministry of Education, Culture, Sports, Science, and Technology, Japan.

Institutional Review Board Statement: Not applicable.

Informed Consent Statement: Not applicable.

Data Availability Statement: Data of the compounds are available from the author.

Acknowledgments: We would like to thank Hideki Waragai and Aiko Sakamoto at the University of Tokyo for measurements of absolute quantum yield in the solid state and elemental analysis. Single-crystal X-ray diffraction measurements were supported by the University of Tokyo Advanced Characterization Nanotechnology Platform in the Nanotechnology Platform Project sponsored by the Ministry of Education, Culture, Sports, Science and Technology (MEXT), Japan, Grant Number, JPMXP09A20UT0224 and JPMXP09A21UT0023.

Conflicts of Interest: The authors declare no conflict of interest.

Sample Availability: Samples of the compounds are available from the authors.

\section{References}

1. Wallesch, M.; Volz, D.; Zink, D.M.; Schepers, U.; Nieger, M.; Baumann, T.; Bräse, S. Bright Coppertunities: Multinuclear CuI Complexes with N-P Ligands and Their Applications. Chem. Eur. J. 2014, 20, 6578-6590. [CrossRef]

2. Armaroli, N. Photoactive mono- and polynuclear $\mathrm{Cu}(\mathrm{i})$-phenanthrolines. A viable alternative to $\mathrm{Ru}(\mathrm{ii})-$ polypyridines? $\mathrm{Chem}$. Soc. Rev. 2001, 30, 113-124. [CrossRef]

3. Tsubomura, T.; Tsukuda, T.; Matsumoto, K. Luminescent d10 transition metal complexes. Bull. Jpn. Soc. Coord. Chem. 2008, 52, 29-42. [CrossRef]

4. Kobayashi, A.; Kato, M. Stimuli-responsive Luminescent Copper(I) Complexes for Intelligent Emissive Devices. Chem. Lett. 2017, 46, 154-162. [CrossRef] 
5. Ford, P.C.; Cariati, E.; Bourassa, J. Photoluminescence Properties of Multinuclear Copper(I) Compounds. Chem. Rev. 1999, 99, 3625-3648. [CrossRef]

6. Czerwieniec, R.; Leitl, M.J.; Homeier, H.H.H.; Yersin, H. Cu(I) complexes-Thermally activated delayed fluorescence. Photophysical approach and material design. Coord. Chem. Rev. 2016, 325, 2-28.

7. Tsuge, K.; Chishina, Y.; Hashiguchi, H.; Sasaki, Y.; Kato, M.; Ishizaka, S.; Kitamura, N. Luminescent copper(I) complexes with halogenido-bridged dimeric core. Coord. Chem. Rev. 2016, 306, 636-651. [CrossRef]

8. Yam, V.W.-W.; Au, V.K.-M.; Leung, S.Y.-L. Light-Emitting Self-Assembled Materials Based on d8 and d10 Transition Metal Complexes. Chem. Rev. 2015, 115, 7589-7728. [CrossRef] [PubMed]

9. McMillin, D.R.; McNett, K.M. Photoprocesses of Copper Complexes That Bind to DNA. Chem. Rev. 1998, 98, 1201-1220. [CrossRef] [PubMed]

10. Yersin, H.; Czerwieniec, R.; Shafikov, M.Z.; Suleymanova, A. TADF Material Design: Photophysical Background and Case Studies Focusing on CuI and AgI Complexes. Chem. Phys. Chem. 2017, 18, 3508-3535. [CrossRef]

11. Armaroli, N.; Accorsi, G.; Cardinali, F.; Listorti, A. Photochemistry and Photophysics of Coordination Compounds: Copper. In Photochemistry and Photophysics of Coordination Compounds I.; Balzani, V., Campagna, S., Eds.; Springer: Berlin, Germany, 2007; Volume 280, pp. 69-115.

12. Peng, R.; Li, M.; Li, D. Copper(I) halides: A versatile family in coordination chemistry and crystal engineering. Coord. Chem. Rev. 2010, 254, 1-18. [CrossRef]

13. Blake, A.J.; Brooks, N.R.; Champness, N.R.; Hanton, L.R.; Hubberstey, P.; Schroder, M. Copper(I) Halide Supramolecular Networks Linked by N-heterocyclic Donor Bridging Ligands. Pure Appl. Chem. 1998, 70, 2351-2357. [CrossRef]

14. Xu, H.; Chen, R.; Sun, Q.; Huang, W.; Liu, X. Recent progress in Metal-Organic Complexes for Optoelectronic Applications. Chem. Soc. Rev. 2014, 43, 3259-3302. [CrossRef] [PubMed]

15. Liu, Y.; Yiu, S.-C.; Ho, C.-L.; Wong, W.-Y. Recent advances in copper complexes for electrical/light energy conversion. Coord. Chem. Rev. 2018, 375, 514-557. [CrossRef]

16. Vitale, M.; Ford, P.C. Luminescent mixed ligand copper(I) clusters (CuI)n(L)m ( $\mathrm{L}=$ pyridine, piperidine): Thermodynamic control of molecular and supramolecular species. Coord. Chem. Rev. 2001, 219-221, 3-16. [CrossRef]

17. Araki, H.; Tsuge, K.; Sasaki, Y.; Ishizaka, S.; Kitamura, N. Luminescence Ranging from Red to Blue: A Series of Copper(I)-Halide Complexes Having Rhombic $\left\{\mathrm{Cu}^{2}(\mu-\mathrm{X})^{2}\right\}(\mathrm{X}=\mathrm{Br}$ and I) Units with N-Heteroaromatic Ligands. Inorg. Chem. 2005, 44, 9667-9675. [CrossRef] [PubMed]

18. Lv, L.; Wang, S.; Liu, W. Copper iodide organic-inorganic hybrid chelating clusters as luminescent coating materials. Inorg. Chim. Acta 2021, 518, 120241. [CrossRef]

19. Starosta, R.; Puchalska, M.; Cybinska, J.; Barysa, M.; Mudring, A.V. Structures, electronic properties and solid state lumi-nescence of $\mathrm{Cu}(\mathrm{I})$ iodide complexes with 2,9-dimethyl-1,10-phenanthroline and aliphatic aminomethylphosphines or tri-phenylphosphine. Dalton Trans. 2011, 40, 2459-2468. [CrossRef] [PubMed]

20. Phifer, C.C.; McMillin, D.R. The basis of aryl substituent effects on charge-transfer absorption intensities. Inorg. Chem. 1986, 25, 1329-1333. [CrossRef]

21. Miller, M.T.; Gantzel, P.K.; Karpishin, T.B. A Highly Emissive Heteroleptic Copper(I) Bis(phenanthroline) Complex: $[\mathrm{Cu}(\mathrm{dbp})(\mathrm{dmp})]+(\mathrm{dbp}=2,9$-Di-tert-butyl-1,10-phenanthroline; dmp = 2,9-Dimethyl-1,10-phenanthroline $) . \quad J$. Am. Chem. Soc. 1999, 121, 4292-4293. [CrossRef]

22. Alkan-Zambada, M.; Constable, E.C.; Housecroft, C.E. The role of percent volume buried in the characterization of cop-per(I) complexes for lighting purposes. Molecules 2020, 25, 2647. [CrossRef] [PubMed]

23. Eggleston, M.K.; McMillin, D.R.; Koenig, K.S.; Pallenberg, A.J. Steric Effects in the Ground and Excited States of Cu(NN) ${ }^{2+}$ Systems. Inorg. Chem. 1997, 36, 172-176. [CrossRef]

24. Omoto, K.; Nakae, T.; Nishio, M.; Yamanoi, Y.; Kasai, H.; Nishibori, E.; Mashimo, T.; Seki, T.; Ito, H.; Nakamura, K.; et al. Thermosalience in macrocycle-based soft crystals via anisotropic deformation of disilanyl ar-chitecture. J. Am. Chem. Soc. 2020, 142, 12651-12657. [CrossRef]

25. Shimada, M.; Tsuchiya, M.; Sakamoto, R.; Yamanoi, Y.; Nishibori, E.; Sugimoto, K.; Nishihara, H. Bright Solid-State Emission of Disilane-Bridged Donor-Acceptor-Donor and Acceptor-Donor-Acceptor Chromophores. Angew. Chem. Int. Ed. 2016, 55, 3022-3026. [CrossRef] [PubMed]

26. Nakae, T.; Nishio, M.; Usuki, T.; Ikeya, M.; Nishimoto, C.; Ito, S.; Maeda, H.; Nishihara, H.; Hattori, M.; Jimura, K.; et al. Luminescent behavior elucidation of disilane-bridged D-A-D triad composed of phenothiazine and thienopyradine. Angezw. Chem. Int. Ed. 2021, 60, 22871-22878. [CrossRef]

27. Hirata, S.; Nishio, M.; Uchida, H.; Usuki, T.; Nakae, T.; Miyachi, M.; Yamanoi, Y.; Nishihara, H. Effect of the Tris(trimethylsilyl)silyl Group on the Fluorescence and Triplet Yields of Oligothiophenes. J. Phys. Chem. C 2020, 124, 3277-3286. [CrossRef]

28. Usuki, T.; Omoto, K.; Shimada, M.; Yamanoi, Y.; Kasai, H.; Nishibori, E.; Nishihara, H. Effects of Substituents on the Blue Luminescence of Disilane-Linked Donor-Acceptor-Donor Triads. Molecules 2019, 24, 521. [CrossRef]

29. Usuki, T.; Shimada, M.; Yamanoi, Y.; Ohto, T.; Tada, H.; Kasai, H.; Nishibori, E.; Nishihara, H. Aggregation-induced En-hanced Emission from Disilane bridged Donor-Acceptor-Donor Luminogens Based on Triarylamine Functionality. ACS Appl. Mater. Interfaces 2018, 10, 12164-12172. [CrossRef] [PubMed] 
30. Shimada, M.; Yamanoi, Y.; Ohto, T.; Pham, S.-T.; Yamada, R.; Tada, H.; Omoto, K.; Tashiro, S.; Shionoya, M.; Hattori, M.; et al. Multifunctional Octamethyltetrasila[2.2]cyclophanes: Conformational Variations, Circularly Polarized Luminescence, and Organic Electroluminescence. J. Am. Chem. Soc. 2017, 139, 11214-11221. [CrossRef]

31. Shimada, M.; Yamanoi, Y.; Matsushita, T.; Kondo, T.; Nishibori, E.; Hatakeyama, A.; Sugimoto, K.; Nishihara, H. Optical Properties of Disilane-Bridged Donor-Acceptor Architectures: Strong Effect of Substituents on Fluorescence and Nonline-ar Optical Properties. J. Am. Chem. Soc. 2015, 137, 1024-1027. [CrossRef] [PubMed]

32. Inubushi, H.; Hattori, Y.; Yamanoi, Y.; Nishihara, H. Structures and optical properties of tris(trimethylsilyl)silylated oligothiophene derivatives. J. Org. Chem. 2014, 79, 2974-2979. [CrossRef] [PubMed]

33. Lesbani, A.; Kondo, H.; Sato, J.-I.; Yamanoi, Y.; Nishihara, H. Facile synthesis of hypersilylated aromatic compounds by palladium-mediated arylation reaction. Chem. Commun. 2010, 46, 7784-7786. [CrossRef] [PubMed]

34. Shimada, M.; Yamanoi, Y.; Nishihara, H. Unusual reactivity of group 14 hydrides toward organic halides: Synthetic stud-ies and application to functional materials. J. Synth. Org. Chem. Jpn. 2016, 74, 1098-1107. [CrossRef]

35. Nakae, M.; Nishio, M.; Yamanoi, Y. Photofunctional Organosilicon Compounds. Bull. Jpn. Soc. Coord. Chem. 2020, 76, 31-39. [CrossRef]

36. Gualco, P.; Amgoune, A.; Miqueu, K.; Ladeira, S.; Bourissou, D. A Crystalline $\sigma$ Complex of Copper. J. Am. Chem. Soc. 2011, 133, 4257-4259. [CrossRef] [PubMed]

37. Burns, D.A.; Press, E.M.; Siegler, M.A.; Klausen, R.S.; Thoi, V.S. 2D Oligosilyl Metal-Organic Frameworks as Multi-state Switchable Materials. Angew. Chem. Int. Ed. 2020, 59, 763-767. [CrossRef] [PubMed]

38. Choi, E.; Lee, H.; Noh, T.H.; Jung, O.-S. In situ crystalline transformation of bis(halo)mercury(ii) coordination polymers to ionic chloro-bridged-bis(halo)mercury(ii) species via UV irradiation in chloroform media. Cryst. Eng. Comm. 2016, 18, 6997-7002. [CrossRef]

39. Sculfort, S.; Braunstein, P. Intramolecular d10-d10 interactions in heterometallic clusters of the transition metals. Chem. Soc. Rev. 2011, 40, 2741-2760. [CrossRef]

40. Cordero, B.; Gómez, V.; Platero-Prats, A.E.; Revés, M.; Echeverría, J.; Cremades, E.; Barragán, F.; Alvarez, S. Covalent radii revisited. Dalton Trans. 2008, 2832-2838. [CrossRef]

41. Labrum, N.S.; Chen, C.-H.; Caulton, K.G. A new face for bis(pyrazol-3-yl)pyridine: Incompatible geometric preferences dictates unprecedented pincer ligand connectivity. Inorg. Chim. Acta. 2019, 485, 54-57. [CrossRef]

42. Starosta, R.; Komarnicka, U.K.; Puchalska, M. Solid state luminescence of CuI and CuNCS complexes with phenanthrolines and a new tris(aminomethyl)phosphine derived from N-methyl-2-phenylethanamine. J. Lumin. 2014, 145, 430-437. [CrossRef]

43. Niu, Y.; Zhang, N.; Hou, H.; Zhu, Y.; Tang, M.; Ng, S.W. Adaptable metal cluster block: Facile construction of photolu-minescent CuI coordination polymeric clusters with metal (I) iodides. J. Mol. Struct. 2007, 827, 195-200. [CrossRef]

44. Khandar, A.A.; Butcher, R.J.; Abedi, M.; Hosseini-Yazdi, S.A.; Akkurt, M.; Tahir, M.N. Synthesis, characterization and crystal structures of dinuclear macrocyclic Schiff base copper(I) complexes bearing different bridges. Polyhedron 2010, 29, 3178-3182 [CrossRef]

45. Nishio, M.; Shimada, M.; Omoto, K.; Nakae, T.; Maeda, H.; Miyachi, M.; Yamanoi, Y.; Nishibori, E.; Nakayama, N.; Goto, H.; et al. Selective formation of SHG active and inactive 1,1,2,2-tetramethyl-1-(4-(N,N-dimethylamino)phenyl)-2-(2'-cyanophenyl)disilane crystals under weak external stimuli. J. Phys. Chem. C 2020, 124, 17450-17458. [CrossRef]

46. Hong, X.-J.; Liu, X.; Zhang, J.-B.; Lin, C.-L.; Wu, X.; Ou, Y.-J.; Yang, J.; Jin, H.-G.; Cai, Y.-P. Two low-dimensional Schiff base copper(i/ii) complexes: Synthesis, characterization and catalytic activity for degradation of organic dyes. Cryst. Eng. Comm. 2014, 16, 7926-7932. [CrossRef]

47. Wheaton, A.M.; Streep, M.E.; Ohlhaver, C.M.; Nicholas, A.D.; Barnes, F.H.; Patterson, H.H.; Pike, R.D. Alkyl Pyridinium Iodocuprate(I) Clusters: Structural Types and Charge Transfer Behavior. ACS Omega 2018, 3, 15281-15292. [CrossRef]

48. Liu, G.-N.; Zhao, R.-Y.; Xu, H.; Wang, Z.-H.; Liu, Q.-S.; Shahid, M.Z.; Miao, J.-L.; Chen, G.; Li, C. The structures, water stabilities and photoluminescence properties of two types of iodocuprate(i)-based hybrids. Dalton Trans. 2018, 47, 2306-2317. [CrossRef]

49. Bai, S.-Q.; Jiang, L.; Sun, B.; Young, D.J.; Hor, T.S.A. Five Cu(i) and Zn(ii) clusters and coordination polymers of 2-pyridyl-1,2,3triazoles: Synthesis, structures and luminescence properties. Cryst. Eng. Comm. 2015, 17, 3305-3311. [CrossRef]

50. Letko, C.S.; Rauchfuss, T.B.; Zhou, X.; Gray, D.L. Influence of Second Coordination Sphere Hydroxyl Groups on the Reactivity of Copper(I) Complexes. Inorg. Chem. 2012, 51, 4511-4520. [CrossRef]

51. Díez-Viñuela, J.S.; Gamasa, M.P.; Panera, M. Tetra-, Di-, and Mononuclear Copper(I) Complexes Containing (S,S)-iPr-pybox and (R,R)-Ph-pybox Ligands. Inorg. Chem. 2006, 45, 10043-10045. [CrossRef]

52. Bai, S.-Q.; Jiang, L.; Young, D.J.; Hor, T.S.A. Luminescent [Cu4I4] aggregates and [Cu3I3]-cyclic coordination polymers supported by quinolyl-triazoles. Dalton Trans. 2015, 44, 6075-6081. [CrossRef] [PubMed]

53. Sarkara, M.; Pandeya, P.; Bera, J.K. Chiral 1,8-naphthyridine based ligands: Syntheses and characterization of Di- and tetranuclear copper (I) and silver (I) complexes. Inorg. Chim. Acta. 2019, 486, 518-528. [CrossRef]

54. Kirst, C.; Reichel, M.; Karaghiosoff, K. Coordination complexes of di(2-pyridyl)ketone with copper(I) and their formation in solution and under solvent-free conditions. Inorg. Chim. Acta. 2021, 514, 119951. [CrossRef]

55. Zhang, X.; Liu, W.; Wei, G.Z.; Banerjee, D.; Hu, Z.; Li, J. Systematic Approach in Designing Rare-Earth-Free Hybrid Sem-iconductor Phosphors for General Lighting Applications. J. Am. Chem. Soc. 2014, 136, 14230-14236. [CrossRef] 
56. Artem'ev, A.V.; Ryzhikov, M.R.; Taidakov, I.V.; Mariana, I.; Rakhmanova, M.I.; Varaksina, E.A.; Bagryanskaya, I.Y.; Malyshev, S.F.; Belogorlov, N.A. Bright green-to-yellow emitting $\mathrm{Cu}(\mathrm{I})$ complexes based on bis(2-pyridyl)phosphine ox-ides: Synthesis, structure and effective thermally activated-delayed fluorescence. Dalton Trans. 2018, 47, 2701-2710. [CrossRef]

57. Cariati, E.; Bu, X.; Ford, P.C. Solvent- and Vapor-Induced Isomerization between the Luminescent Solids [CuI(4-pic)]4 and $[\mathrm{CuI}(4-$ pic) $] \infty$ (pic = methylpyridine). The Structural Basis for the Observed Luminescence Vapochromism. Chem. Mater. 2000, 12, 3385-3391. [CrossRef]

58. Shimizu, M.; Oda, K.; Bando, T.; Hiyama, T. Preparation, Structure, and Properties of Tris(trimethylsilyl)silyl-substituted Anthracenes: Realization of Ideal Conformation for $\sigma-\pi$ Conjugation Involving Eclipse of Si-Si $\sigma$-Bond with p-Orbital of Aromatic Ring. Chem. Lett. 2006, 35, 1022-1023. [CrossRef]

59. Imae, I.; Minami, T.; Kawakami, Y. Electrochemical properties and estimation of HOMO and LUMO levels of permethyl-ated oligosilanes with well-defined structures. Des. Monomers Polym. 2004, 7, 127-133. [CrossRef]

60. Ohshita, J.; Nodono, M.; Kai, H.; Watanabe, T.; Kunai, A.; Komaguchi, K.; Shiotani, M.; Adachi, A.; Okita, K.; Harima, Y.; et al. Synthesis and Optical, Electrochemical, and Electron-Transporting Properties of Silicon-Bridged Bithiophenes. Organometallics 1999, 18, 1453-1459. [CrossRef]

61. Kato, M. Luminescent Copper(I) Complexes Exhibiting Chromic Phenomena. Nihon Kessho Gakkaishi 2015, 57, 110-115. [CrossRef]

62. Yuan, S.; Wang, H.; Wang, D.-X.; Lu, H.-F.; Feng, S.-Y.; Sun, D. Reactant ratio-modulated six new copper(I)-iodide coor-dination complexes based on diverse [CumIm] aggregates and biimidazole linkers: Syntheses, structures and temperature-dependent luminescence properties. Cryst. Eng. Comm. 2013, 15, 7792-7802. [CrossRef]

63. Wang, R.-Y.; Zhang, X.; Yang, Q.-F.; Huo, Q.-S.; Yu, J.-H.; Jia-Ning Xu, J.-N.; Xu, J.-Q. New copper(I) iodides with bisim-idazole molecules: Synthesis, structural characterization and photoluminescence property. J. Solid State Chem. 2017, 251, 176-185. [CrossRef]

64. Zollinger, H. Color Chemistry: Synthesis, Properties and Applications of Organic Dyes and Pigments. Leon 1989, $22,456$. [CrossRef]

65. Hong, Y.; Lam, J.W.Y.; Tang, B.Z. Aggregation-induced emission. Chem. Soc. Rev. 2011, 40, 5361-5388. [CrossRef] [PubMed]

66. Birks, J.B. Photophysics of Aromatic Molecules; Wiley: London, UK, 1970. 